\title{
Magnetorheological Fluid Damper : A Research
}

\author{
Sanjay Kumar, Ajay Kumar
}

\begin{abstract}
Vibration signs suggest system's wellbeing. It frees that the requirement of bringing vibration intensity to limitation. Researchers have been focusing on several different varieties of vibration isolators as well as also their calculating regarding space involvement, dependability, price and fat. Inside this newspaper, an endeavor was designed to present the most basic theories of Magnetorheological Fluids (MRF) that may function as a more semi-active vibration isolator, for its rookies and investigators.
\end{abstract}

\section{INTRODUCTION}

Vibrations at a system are all as a result of the characterization of vitality. Efforts should be manufactured to minimize the degree of vibration to expand their machine's life span. Vibration isolation could be. The demand for vibration isolation is growing more and more crucial for precision structures and engineering gear that are sensitive. Additionally, it's getting crucial to look apparatus having more compact dimension, a greater bandwidth, and also power demand. Controller Has Lately become a Region of attention Due to Its Capability to Give the adaptability of apparatus without needing a more electricity source that is Substantial for actuators. Controller was grown as a compromise among passive and inactive controller. Rather than conflicting a disturbance as could be true with controller that is busy, a push is applied by semi-active manage strategy. Even a management system can't offer energy into some machine containing actuator and also both the arrangement, nonetheless nevertheless, it might perform outcomes that are positive by changing this system's attributes and stiffness [1].The eye might be credited to how semi-active command apparatus provide you the adaptability of controller apparatus without needing the energy resources that were related. Additionally, as previously mentioned previously, semi-active command apparatus usually would not need the capacity to destabilize (from the bounded input/bounded out-put awareness) the structural operation. Scientific reports have suggested that employing techniques to function better compared to apparatus also possess the possibility to accomplish most of the operation of procedures that were busy allowing for the chance of response decrease that was successful throughout a vast selection of loading requirements $[2,5]$.

\section{CHARACTERISTICS OF MR FLUID}

Just lately, a fact desirable and efficient semi-active technique comprising Magnetorheological liquid (MRF)

Revised Version Manuscript Received on 10 September, 2019.

Sanjay Kumar, Mechanical Engineering, Noida Institute of Engineering and Technology, Noida, U.P. India.

(Email: research.paper@niet.co.in)

Ajay Kumar, Mechanical Engineering, Noida Institute of Engineering and Technology, Noida, U.P. India.

(Email: research.paper@niet.co.in).

\section{dampers was suggested by most researchers [6 8]}

Magnetorheological can be a division of theology that addresses deformation and the stream of these substances. Instead, they can switch reversibly getting compacted yield power underneath a magnetic field [9]. Their obvious viscosity varies considerably (105-106 days) in just a couple milliseconds, if the magnetic field is implemented. Even the forces arising out of your connections result in your material using viscosity. As exhibited at Fig this dipolar interaction is accountable for that series such as creation of those particles from the direction of their industry. 1 [9]. Particles maintained by magnetic area and also these particles' chains withstand without breaking up, making them act as a great with some degree of shear strain. This happening develops a return to stress, which will increase since the size of the field rises [10]. Some of many benefits of MR fluids would be that your return street price that is greater. Minimal voltage electrical electricity provides for MR fluids [11] and temperature equilibrium among $--+150{ }^{\circ} \mathrm{C}$ and also forty ${ }^{\circ} \mathrm{C}$ create sure they are substances for vibration isolation. Since soon because the area is removed away, the MR liquid needs to come into some condition in milliseconds magnetization have been popular. Owing to the very lower saturation magnetization carbonyl iron powder is apparently the principal cycle on MR liquid compositions that are functional. MR fluids are ready according to ferromagnetic substances for example manganese-zinc ferrite and also nickel zinc rewrite of a typical magnitude of two $\mu \mathrm{m}$. The robustness along with the uncomplicated mechanical style and style of Magnetorheological (MR) dampers create sure they are a clear option to get a semi-active controller apparatus. They might need energy whilst delivering drives acceptable for full-scale software. They truly have been failing safe since they act as apparatus in the event of an energy reduction [13].MR apparatus may be split into some mix of those three or three classes of manners predicated around the plan of this apparatus [10, 12]. From the valve/shear manner 1 surface goes in accordance with the liquid. This motion makes a shear pressure from the liquid. The shear power of this fluid could possibly be different from using different heights of the arena. From the manner, the liquid will be pressurized to stream. Also the stress of this fluid and also the circulation speed could be corrected by changing the magnetic industry. From the stem picture manner, two surfaces that are parallel to squeeze the liquid in-between also the movement of this fluid will be vertical compared to the surfaces. The magnetic field that is determining the drive needed to compress the liquid as well as the rate of these 
surfaces throughout the milling motion [14]. A circuit is critical to induce the fluctuations in the MR fluid's viscosity. By utilizing Kirchoffer s Legislation of magnetic circuits, the mandatory variety of amp-turns (NI) will be

$$
\mathrm{NI}=\sum \mathrm{HiLi}=\mathrm{Hfg}+\mathrm{Hs} \mathrm{L}
$$

At which Hs and I would be the magnetic field strength of this fluid and also the metal gram is the length of the gap at which the liquid escapes, and $\mathrm{L}$ is the size of this steep trail. By equation (1)), it's obvious the to boost the entire magnetic field strength, the amount of all amp-turns must get retained in a man whilst decreasing the length of the liquid gap and also the steel trail. But of metal has to be kept like the field strength from the metal is lower. Additionally, a difference that is overly tiny could bring about the drive when no field is put on, to become high. Carbon dioxide, that includes a very high permeability and equilibrium is typically used by the circuit. Level is effortlessly directed by this metal into the pit.

\section{PROPERTIES OF MR FLUID \& RESULTS}

Even the MR fluids over the pre- return area exhibit all therefore and qualities are vital particularly.MR damper Several layouts of MR dampers analyzed and are assembled previously. The very first of those layouts would be that the skip damper, wherever in fact the skip leak does occur beyond the tube along with also an electro-magnet employs a magnetic field towards the skip duct [15]. Inside this setup, the damper includes an outside and internal casing. The housing guides the piston pole gathering, at the exact identical fashion like in a tube damper. The quantity enclosed by the casing is referred to. The quantity that's characterized from the distance between the casing and also your casing is described since the diameter. Therefore, no air pockets exist, the reservoir is full of MR liquid. Almost all of those dampers have been created for software like vibration isolation of even bridges and even structures. A terminal, double-shaft MR damper together using the electro-magnet placed in the canister is acceptable for small software and it is designed to be used with concurrent stage mechanics through which a damper will correct the damping in just about every leg connector of this mechanism. Even the damper works at a blend of lead crystal and also valve shear manners. There is A magnetic field done throughout using the coil that's wrapped across the human anatomy that was human along this difference. Once the field is used, this fluid's viscosity grows within an issue of milliseconds. THE-FIELD induces a resistance. This way is corrected by massaging a detector signal that is conditioned into the coil. MR dampers are useful for bike software [17] gun recoil software [18] applications, and also for construction influence motion brought on earthquakes and by gusts of wind.

Challenges: A) Dimensions of MR dampers confine their usage in marine applications. Style of MR dampers smaller in proportions has to be explored. B) Behavior of MR dampers which makes it tough to invent control plans to restrain both the shaking. This impact has to be investigated to get a grip on plans farther must get explored to restrain the shaking at varying requirements. Dyke and Jansen had performed studies. Dependability and maintainability ought to be investigated to guarantee achievements.

E) Principle of MR dampers in Genuine Constructions. A number of researches have been performed on software of MR damper in auto business, Educate suspension Technique, seismic security of structures, cable- stayed bridges

F) To raise the self sufficiency of this damping program, investigations in to creation of a self-powered MR damper ought to be pursued.

\section{CONCLUSION}

The capacity to peep into the rheological qualities of Magnetorheological (MR) fluids has caused vast analysis chances while within the area of mechanical shaking manage. Chances have led research workers to research such issues because adaptive or semi-active vibration control; an essential and promising application from the attenuation of vibrations. Software will soon be have been Increasing and at the long run Driven by gear manufacturers appearing to increase in value throughout the debut of fluids. Three locations may function both automotive, civil and aerospace engineering.

\section{REFERENCES}

1. G. Bossis, O. Volkova, Y. Grasselli, and A. Ciffreo, "The Role of Volume Fraction and Additives on the Rheology of Suspensions of Micron Sized Iron Particles," Front. Mater., vol. 6, Feb. 2019.

2. S. Gurgen, M. C. Kushan, and W. Li, "Shear thickening fluids in protective applications: A review," Prog. Polym. Sci., vol. 75, pp. 48-72, Dec. 2017.

3. I. Bica, M. Balasoiu, M. Bunoiu, and L. Iordaconiu, "MICROPARTICLES AND ELECTROCONDUCTIVE MAGNETORHEOLOGICAL SUSPENSIONS," Rom. J. Phys., vol. 61, no. 5-6, pp. 926-945, 2016.

4. N. Caterino, B. M. Azmoodeh, and A. Occhiuzzi, "Medium to long term behavior of MR dampers for structural control," SMART Mater. Struct., vol. 23, no. 11, Nov. 2014.

5. J. Marx, A. Schreiber, and P. Zapp, "Response to 'Life-cycle green-house gas emissions of onshore and offshore wind turbines'," J. Clean. Prod., vol. 219, pp. 33 34, May 2019.

6. J. S. Jeon, "How housing market responds to greenbelt relaxation: Case of Seoul Metropolitan Area, South Korea," Land use policy, vol. 84, pp. 328-334, May 2019.

7. A. C. Serrenho, M. Drewniok, C. Dunant, and J. M. Allwood, "Testing the greenhouse gas emissions reduction potential of alternative strategies for the english housing stock," Resour. Conserv. Recycl., vol. 144, pp. 267-275, May 2019.

8. K. Laszlo, L. Morin, and C. L. Veeder, "PREDICTORS OF PAIR HOUSING SUCCESS VARY IN CAPTIVE ST. KITTS AFRICAN GREEN MONKEYS (CHLOROCEBUS SABAEUS) VERSUS CAPTIVE TANZANIAN AFRICAN GREEN MONKEYS (CHLOROCEBUS PYGERYTHRUS)," Am. J. Primatol., vol. 80, no. 1, SI, Dec. 2018. 
9. X. (Jason) Cao and S. Lou, "When and How Much Did the Green Line LRT Increase Single-Family Housing Values in St. Paul, Minnesota?," J. Plan. Educ. Res., vol. 38, no. 4, pp. 427-436, Dec. 2018.

10. T. B. Hammed, S. O. Wandiga, Y. Mulugetta, and M. K. C. Sridhar, "Improving knowledge and practices of mitigating green house gas emission through waste recycling in a community, Ibadan, Nigeria," WASTE Manag., vol. 81, pp. 22-32, Nov. 2018.

11. S. Geng and L. Lin, "The extensible evaluation framework of urban green house gas emission reduction responsibility: A case of Shandong province in China," ENERGY, vol. 162, pp. 171-184, Nov. 2018.

12. B. L. Simon, "Sense and sensibility: Dual knowledge bases of Greenwich House, NYC, 1902-1920," Qual. Soc. Work, vol. 17, no. 6, pp. 814-831, Nov. 2018.

13. A. Rigolon and J. Nemeth, "'We're not in the business of housing: $\{"\}$ Environmental gentrification and the nonprofitization of green infrastructure projects," CITIES, vol. 81, pp. 71-80, Nov. 2018.

14. L. Zhang, J. Wu, and H. Liu, "Policies to enhance the drivers of green housing development in China," Energy Policy, vol. 121, pp. 225-235, Oct. 2018.

15. R. de Graaf, "High-Risers: Cabrini-Green and the Fate of American Public Housing," New York Rev. Books, vol. 65 , no. 14 , pp. $67-70$, Sep. 2018.

16. A. G. Gel and E. Satiroglu, "DETERMINATION OF OPEN GREEN SPACE USAGE IN HOUSING ESTATES," OPEN HOUSE Int., vol. 43, no. 3, pp. 5968, Sep. 2018

17. A. Nowoswiat, J. Slusarek, R. Zuchowski, and B. Pudelko, "The Impact of Noise in the Environment on the Acoustic Assessment of Green Houses," Int. J. Acoust. Vib., vol. 23, no. 3, pp. 392-401, Sep. 2018.

18. H.-C. Park and M. K. Patel, "Naphtha storage fraction and green house gas emissions in the Korean petrochemical industry," ENERGY Environ., vol. 29, no. 6, pp. 919 937, Sep. 2018.

19. G. H. Park and S. M. Kwon, "The ameliorated trade-off between commuting efficiency and jobs-housing balance in a green-belted city: Lessons from Seoul," Socioecon. Plann. Sci., vol. 63, pp. 47-59, Sep. 2018. 